\title{
The Study of Wear in Titanium Material
}

\author{
${ }^{*}$ S. Anandan ${ }^{1}$, R. Rajesh ${ }^{2}$ and K. Ganesh ${ }^{3}$ \\ ${ }^{1}$ Scientific Officer, Nuclear Training Center, Kudankulam Nuclear Power Project, Kudankulam, \\ India. \\ ${ }^{2} H O D$, Mechanical Engineering Dept., Noorul Islam University, Kumarakoil, India. \\ ${ }^{3}$ Global Business Services-Global Delivery, IBM India Private Limited,, IL \& FS Financial \\ Center, Bandra East, Mumbai 40051, India. \\ Email: *srinivasananandan1964@gmail.com, rajesh1576@yahoo.co.in, koganesh@yahoo.com
}

\begin{abstract}
A country's growth determined by various factor and the energy production is one of the key role for the growth. The electrical energy is decided their global standard. There are many ways to produce the electrical energy. Considering the fossil resources and nuclear resources the condenser is the one, which increase the efficiency of the machine. In the condenser to condensate the steams by condenser cooling water using either the sea water or river water. In the beginning times and subsequent intervals all power stations uses brass, aluminum, copper, stainless steel etc., as the condenser tube materials which is the important to increase the efficiency of the machine. In recent years the application of Titanium is very much useful because of their environment withstands and weight less probability. Including the said factors there are other factors also applicable like corrosion property, strength, chemical and physical properties. Now, almost all the condenser in Nuclear and fossil power stations they are used the condenser tube materials is Titanium and its alloys. The Titanium materials are very much useful for the power stations because of its physical, chemical and corrosion resistance properties and also for less weight probability. To increase the life of the condenser tube, Titanium is recommended as tube materials and also this Titanium will transfer the heat as good as compared to other materials.
\end{abstract}

Though many advantage having the Titanium tube selected for condenser tube there are minimum available study conducted for analyzing the properties of wear of this material. Here in this study the Titanium wear property has been checked by the Pin and Disc Method.

Keywords: Condenser, Wear, Pin \& Disc method

\section{Introduction:}

The Electrical energy is very important in our day today life. There are many ways to produce the electricity. In the Global statics, presently all sources of electrical energy production in total 22,752 Twh. Out of which $40.2 \%$ through coal, $22 \%$ by gas, $16 \%$ produce hydro, $10 \%$ by nuclear, further $2.8 \%$ solar \& wind and $7.5 \%$ of other sources of energy. Out of which the fossil and nuclear power generation, the condenser is the part which will increase the efficiency of the machine. Here in this study the condenser tube which is used Titanium material having lot of positive affects and less study about their wear have been made, this paper brings the wear property of the Titanium materials.

Received: 02 August, 2017; Revised: 23 October, 2017; Accepted: 06 January, 2018

*Corresponding Author 


\section{Definition 1.1:}

The continuous and loss of material from the operating place of a body occurring as a result of relative motion of the material is termed as wear.

The condenser in Power stations plays an important role. The diagram of the condenser tube is shown in Figure 1. And also in Figure 2 Schematic presentation of wear sites due to droplet impingement shown. From these two drawings we can easily understand that wear study is inevitable to analysis the Titanium Material.

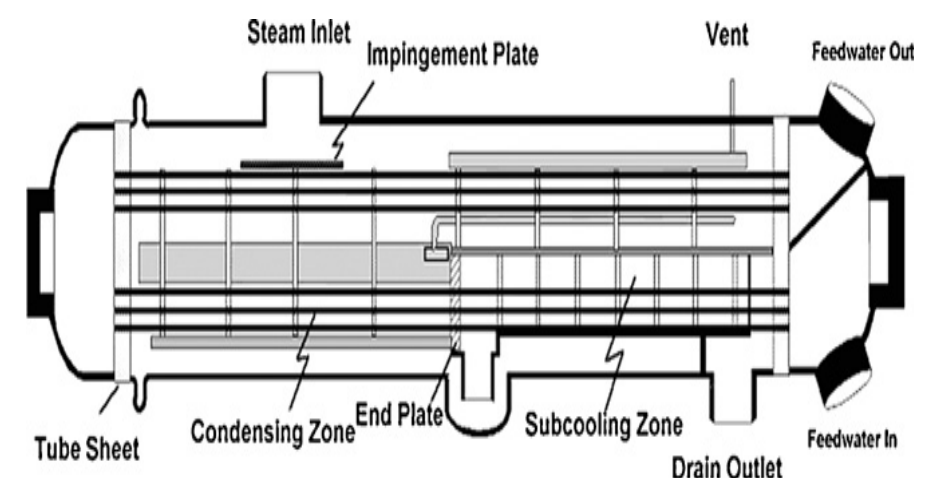

Figure: 1: The schematic presentation of Heat Exchanger in Power Plants

Titanium (Grade 2) material is highly corrosion resistant material, offering an excellent strength and ductility but it has lower strength than titanium alloys.

There has been limited research work carried out to wear properties of Titanium and a considerable enhancement is only achievable by any established. To understand the wear of titanium and predict the wear occurring against the service conditions, a method can be employed involving of experiments. 


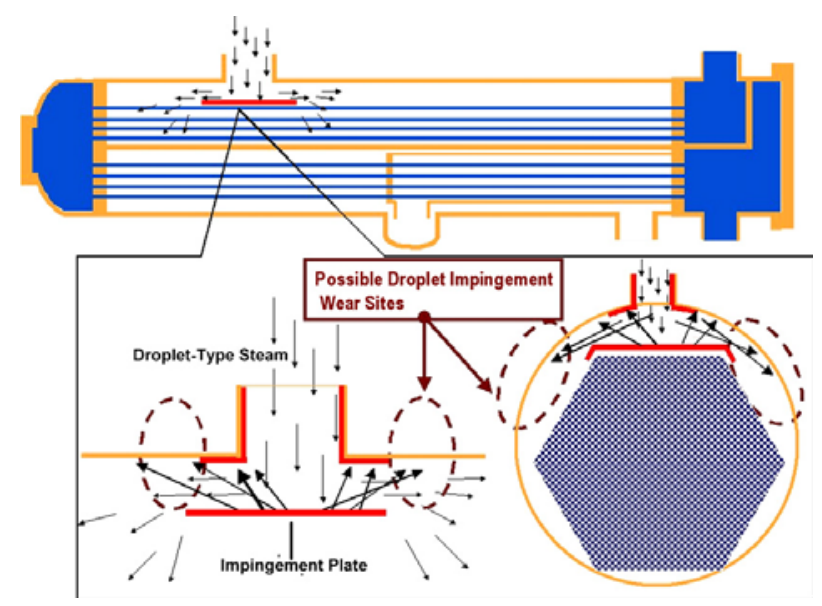

Figure: 2: Schematic presentation of wear sites due to droplet impingement

In this paper, a statistical approach to find the wear in titanium and test has been carried out in various parameters and result has been tabled and conclusion arrived.

\section{Wear Method:-}

Wear test is employed to the experiment for wear study in order to obtain optimum results with limited number of experiments. This experimental involves the use of factors affecting the process and also the levels these factors need to be varied in order to complete the experiment with limited trials to save the time, cost and available resources.

\section{Plan of Experiments}

The parameters and their levels for wear test were carried out on identifying the factors, their levels as shown in Table 1.

\begin{tabular}{|l|l|l|l|}
\hline Levels & Load, KN & $\begin{array}{l}\text { Speed, } \\
\text { RPM }\end{array}$ & Duration, Min \\
\hline 1 & 5 & 100 & 05 \\
\hline 2 & 10 & 200 & 10 \\
\hline 3 & 15 & 300 & 15 \\
\hline
\end{tabular}

Table 1. Parameters and their levels for wear test 
In Table 2, another level of load, speed and duration are considered for analysis.

\begin{tabular}{|l|l|l|l|}
\hline Test run & Load (A) & Speed ( B) & Duration ( C) \\
\hline 1 & 1 & 100 & 05 \\
\hline 2 & 1 & 200 & 10 \\
\hline 3 & 1 & 300 & 15 \\
\hline 4 & 2 & 100 & 10 \\
\hline 5 & 2 & 200 & 15 \\
\hline 6 & 2 & 300 & 05 \\
\hline 7 & 3 & 100 & 15 \\
\hline 8 & 3 & 200 & 05 \\
\hline 9 & 3 & 300 & 10 \\
\hline
\end{tabular}

Table 2. The Method of test carried out

\section{Experimental data}

\subsection{Material}

The Titanium material chosen for this work is grade 2 titanium. The specimen of the material of $6 \mathrm{~mm}$ diameter and $50 \mathrm{~mm}$ length were make ready for wear test with smooth polished ends. The surface was polished.

\subsection{Pin-on-Disc Wear Test}

The pin-on-disc tester machine shown in Figure 3 is used to study the abrasive wear of titanium under dry sliding condition at atmospheric air.

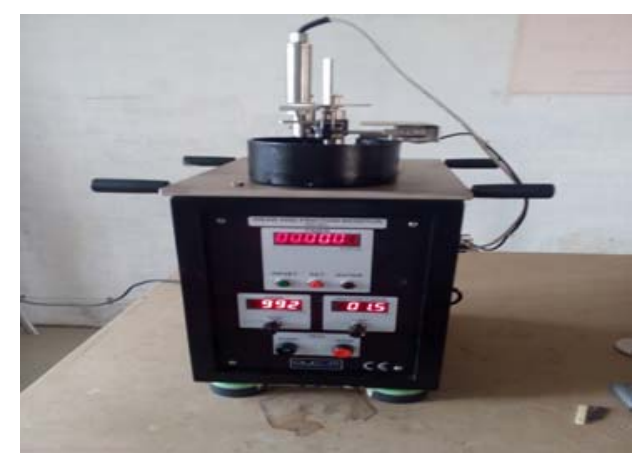

Figure 3: Pin On Disc Testing Machine 
The specimen is tight fit in the pin on disc machine for testing; the load is applied on the specimen with a track radius of $100 \mathrm{~mm}$. The weight loss is measured during the test for the variable parameters of load, speed and duration.

\begin{tabular}{|l|l|l|}
\hline Sl.No & Process Parameters & Specifications \\
\hline 1 & $\begin{array}{l}\text { Wear DiscDiameter, } \\
\text { Thickness }\end{array}$ & $\begin{array}{l}100 \text { Diameter and } 8 \\
\text { mm Thickness }\end{array}$ \\
\hline 2 & Disc Rotation Speed & $100-500$ \\
\hline 3 & Temperature & Room Temperature \\
\hline 4 & Wear Track Diameter & 60 \\
\hline 5 & Load & $10-30$ \\
\hline 6 & Time & $\begin{array}{l}5-15 \text { Min } \\
\text { mm Length }\end{array}$ \\
\hline 7 & Specimen Diameter & \\
\hline
\end{tabular}

Table 3. Specifications for wear testing.

\section{Result and Discussion}

The analysis of wear loss calculated and was carried out. Test conditions with output results are presented in Table 4.

\begin{tabular}{|c|c|c|l|c|}
\hline Load & Speed & Duration & $\begin{array}{l}\text { Mean } \\
\text { Wear } \\
(\mathbf{m g})\end{array}$ & $\begin{array}{l}\text { S/N } \\
\text { Ratio }\end{array}$ \\
\hline 1 & 100 & 5 & 0.1401 & 17 \\
\hline 1 & 200 & 10 & 0.2020 & 14 \\
\hline 1 & 300 & 15 & 0.3275 & 9.5 \\
\hline 2 & 100 & 10 & 0.2355 & 12 \\
\hline 2 & 200 & 15 & 0.3285 & 9.6 \\
\hline 2 & 300 & 5 & 0.2885 & 10 \\
\hline 3 & 100 & 15 & 0.3350 & 9.3 \\
\hline 3 & 200 & 5 & 0.2705 & 11 \\
\hline 3 & 300 & 10 & 0.3885 & 8 \\
\hline
\end{tabular}

Table 4. Wear loss and S/N ratio (Signal - to - Noise Ratio) 


\subsection{S/N Ratio Analysis}

The measure of performance in this method called signal-to-noise ratios $(\mathrm{S} / \mathrm{N})$ which is logarithmic function of desired output to serve as objective function for optimization.

Considering the different facts the $\mathrm{S} / \mathrm{N}$ ratio was calculated for the wear loss of the material. The $\mathrm{S} / \mathrm{N}$ ratio was equation for smaller is better quality characteristic.

$$
\mathrm{S} / \mathrm{N}=-10 \log 10(1 / \mathrm{n}) \sum(\mathrm{yi} 2),
$$

Where $\mathrm{n}$ is the number of observation, and $\mathrm{y}$ is the observed data

The $\mathrm{S} / \mathrm{N}$ ratios were plotted for each factor against each of its levels with a better condition for wear loss and are as shown in Figure 4.

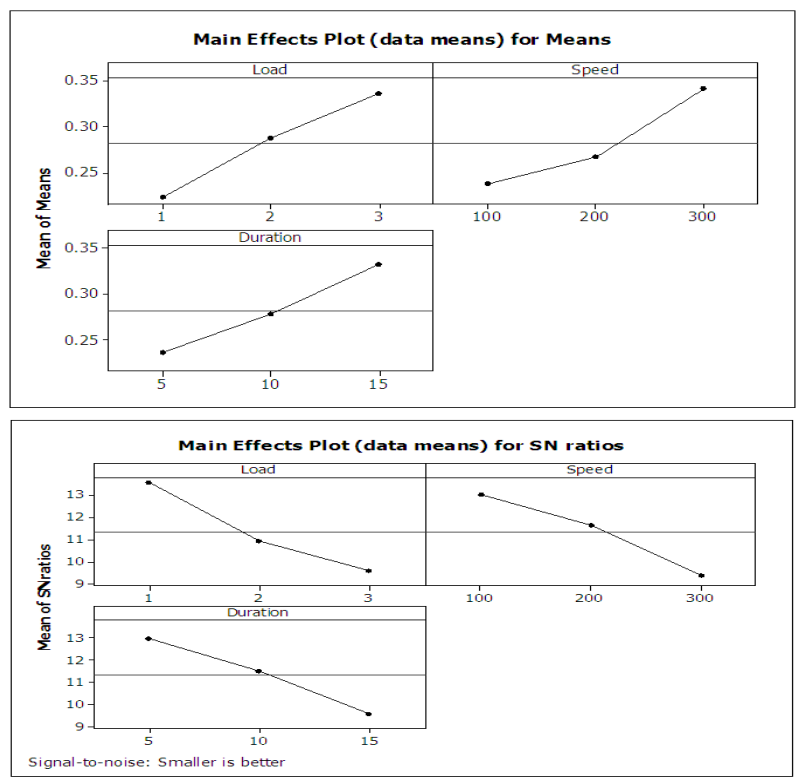

Figure 4: S/N Ration on wear loss

The results leads to the conclusion that the consideration show an increase in wear loss of the material due to get more with increasing of the dependents. The wear loss increases almost linearly with increasing the load (A), the speed (B) and time duration (C). As for minimization of wear is concerned, the combination of $\mathrm{A}, \mathrm{B}$ and $\mathrm{C}$ has significant result; a method of A1, B1 and $\mathrm{C} 1$ gives minimum level of wear. In order to justify/conform the factors a further statistical analysis is necessary i.e. analysis of variance. 


\begin{tabular}{|l|l|l|l|}
\hline Level & Load & Sped & Duration \\
\hline 1 & 13.5 & 13.05 & 12.95 \\
\hline 2 & 10.9 & 11.6 & 11.5 \\
\hline 3 & 9.6 & 6.4 & 9.5 \\
\hline Delta & 3.9 & 3.6 & 3.4 \\
\hline Rank & 1 & 2 & 3 \\
\hline
\end{tabular}

Table 5. Response table for $\mathrm{S} / \mathrm{N}$ Ratio (Smaller is better)

\begin{tabular}{|l|l|l|l|}
\hline Level & Load & Speed & Duration \\
\hline 1 & 0.25 & 0.26 & 0.24 \\
\hline 2 & 0.28 & 0.26 & 0.27 \\
\hline 3 & 0.34 & 0.35 & 0.33 \\
\hline Delta & 0.11 & 0.10 & 0.09 \\
\hline Rank & 1 & 2 & 3 \\
\hline
\end{tabular}

Table 6. Response table for means

\subsection{Analysis of Variance}

A statistical analysis of variance (ANOVA)is a method to find the each process parameters with the help of Taguchi technique for each level of ear loss. The percentages of each level of the test will be estimated by ANOVA. From this method we can easily find the result and this results tabled below.

The Table 7 and 8 shows the results of the ANOVA where the experiments have been carried out for the level of more than $90 \%$. The input with a p-value less than 0.05 were considered to have a statistically to the performance measures. The last column in Table 7 and 8 shows the percentage of each parameter and it can be observed that the load has the highest influence of more than $35 \%$ on wear loss followed by speed and duration considering the $\mathrm{S} / \mathrm{N}$ ratios; the speed and duration have an influence of $32 \%$ and $30 \%$ respectively. Hence load is an important parameter to be considered during abrasive wear of grade 2 titanium followed by speed and duration. 


\begin{tabular}{|l|l|l|l|l|l|l|l|}
\hline Source & DF & Seq SS & Adj SS & $\begin{array}{l}\text { Adj } \\
\text { MS }\end{array}$ & $\begin{array}{l}\text { F } \\
\text { test }\end{array}$ & $\begin{array}{l}\text { P } \\
\text { value }\end{array}$ & $\begin{array}{l}\text { P\% } \\
\text { (Contribution) }\end{array}$ \\
\hline Load & 2 & 23.8 & 23.8 & 11.9 & 12.2 & 0.012 & 37 \\
\hline Speed & 2 & 21.2 & 21.2 & 11.5 & 88.5 & 0.013 & 35 \\
\hline Duration & 2 & 17.5 & 17.5 & 9 & 75 & 0.014 & 27 \\
\hline Error & 2 & 0.3 & 0.3 & 0.2 & & & 1 \\
\hline Total & 8 & 62.8 & & & & & 100 \\
\hline
\end{tabular}

Table 7. Anlysis of Variance of S/N . Using Adjusted SS.

$\mathrm{S}=0.345 \mathrm{R}-\mathrm{Sq}=99.5 \% \mathrm{R}-\mathrm{Sq}(\operatorname{adj})=98.3 \%: \mathrm{DOF}=$ Degrees of freedom Seq SS: sequential Sum of squares: Adj SS: adjusted sum of squares: Adj Ms:adjusted mean squares.

\begin{tabular}{|l|l|l|l|l|l|l|l|}
\hline Source & D & Seq SS & Adj SS & $\begin{array}{l}\text { Adj } \\
\text { MS }\end{array}$ & $\begin{array}{l}\text { F } \\
\text { test }\end{array}$ & $\begin{array}{l}\text { P } \\
\text { value }\end{array}$ & $\begin{array}{l}\text { P\% } \\
\text { (Contribution) }\end{array}$ \\
\hline Load & 2 & 0.018 & 0.018 & 0.008 & 85 & 0.010 & 38 \\
\hline Speed & 2 & 0.017 & 0.017 & 0.007 & 77 & 0.012 & 34 \\
\hline Duration & 2 & 0.015 & 0.015 & 0.006 & 62 & 0.015 & 27 \\
\hline Error & 2 & 0.00028 & $\begin{array}{l}0.0002 \\
8\end{array}$ & $\begin{array}{l}0.000 \\
5\end{array}$ & & & 1 \\
\hline Total & 8 & 62.8 & & & & & 100 \\
\hline
\end{tabular}

Table 8. Analysis of Variance for Mean, Using Adjusted SS for test.

$\mathrm{S}=0.01 \mathrm{R}-\mathrm{Sq}=99.3 \% \mathrm{R}-\mathrm{Sq}(\mathrm{adj})=98.5 \%$ : Degrees of freedom $:$ Seq. SS sequential Sum of squares: Adj SS: adjusted sum of squares: Adj Ms: adjusted mean squares.

\subsection{Multiple Linear Regression Model Analysis}

To establish the correlation between the wear the applied load, the variable speed and time duration with the wear loss multiple linear regression model was used.

Wear Loss $=-0.32+0.045 \mathrm{X}$ Load $+0.0005 \mathrm{X}$ Speed $+0.0095 \mathrm{X}$ Duration.

$\mathrm{S}=0.0175 \mathrm{R}-\mathrm{Sq}=99.4 \% \mathrm{R}-\mathrm{Sq}(\mathrm{adj})=98.4 \%$

The test was carried out by selecting the set of level as shown in Table 9. The Table 10 shows the results achieved, where comparison was noted between the available values from the model developed in the present work (Equation 1), with the values obtained through test. From the analysis of the referred table we can observe that the calculated error varies from $1.5 \%$ to $10.9 \%$ for wear loss. Therefore, the multiple regression equation derived above correlate the evaluation of the wear of the grade 2 titanium with the reasonable degree of calculation. 
The Study of Wear in Tita nium Material

\begin{tabular}{|l|l|l|l|}
\hline Test & Load & Speed & Duration \\
\hline 1 & 1 & 100 & 5 \\
\hline 2 & 2 & 100 & 10 \\
\hline 3 & 3 & 300 & 10 \\
\hline
\end{tabular}

Table 9. Parameter used in the Confirmation test

\begin{tabular}{|l|l|l|l|}
\hline Test & Load & Speed & Duration \\
\hline 1 & 1 & 100 & 5 \\
\hline 2 & 2 & 100 & 10 \\
\hline 3 & 3 & 300 & 10 \\
\hline
\end{tabular}

Table 10. The test with regression model

\subsection{Wear Experiment:}

Wear test is performed to check the obtained results and to calculate the accuracy of the test. The result of the estimated value and the actual value is shown in Table 11 . The improvement of $\mathrm{S} / \mathrm{N}$ ratio from mean to optimum process parameters is $5.5 \mathrm{~dB}$.

\begin{tabular}{|l|l|l|l|}
\hline Level & $\begin{array}{l}\text { Mean } \\
\text { Process } \\
\text { Parameters } \\
\text { ( A2B2C2) }\end{array}$ & \multicolumn{2}{|l}{$\begin{array}{l}\text { Optimum } \\
\text { Parameter (A1B1C1). }\end{array}$} \\
\cline { 3 - 4 } & Predicted & Experimental \\
\hline $\begin{array}{l}\text { Weight } \\
\text { Loss } \\
(\mathrm{mg})\end{array}$ & 0.255 & 0.14 & 0.15 \\
\hline $\begin{array}{l}\text { S/N } \\
\text { Ratio } \\
(\mathrm{dB})\end{array}$ & 11.5 & 17 & 17.2 \\
\hline
\end{tabular}

Table 11. Comparison of confirmation experiment

\section{Conclusion:}

Wear method can be used to check the wear analyzing machine (Pin on Disc) and the result is described in this paper. The following conclusion arrived is listed below: - In the applied Load (37\%) and the speed of about $35 \%$ and testing duration about $27 \%$ been taken consideration in these experiments. 
- In this test the result the linear regression equation has been taken with R-Sq value 99.4\%. Result of this shows that the error associated with the wear loss of the specimen varies from $1.2 \%$ to $8.5 \%$.

- The wear confirmation experiment has shown that an improvement of $5 \mathrm{~dB}$ can be achieved by implementing the optimum process parameters with an error of less than 2$3 \%$ between the experimental and predicted values.

- Finally the Wear test results shows that the material Titanium is withstand the wear level shown above and high in comparison with the other materials.

\section{References:}

[1] G.W. Rowe, Friction, Wear and Lubrication, Organization for Economic Cooperation and Development, Birmingham, Gt. Britain, 1966.

[2] Vaishal J. Banker, Jitendra M. Mistry, Wear mode in Inconel Alloys-A literature study. Proceedings of the Advance materials and Product Design 2015. ISSN No. 978-935196-3: 141-147.

[3] Chandra Mouli, K.V.V. Srinivas, J \& Subbaiah, K.V.Optimisation and Output Forecasting using Taguchi Neural Network Approach IE(I) Journal -PR Vol 86, 2006

[4] Emal Kuram, Babur Ozcelik, Multi-objective optimization using Taguchi based grey relational analysis for micro-milling of A1 7075 material with ball nose and mill. Measurement 2013; 46; 1849-1864.

[5] Gerd Lütjering, James C. Williams. Titanium. $2^{\text {nd }}$ edition, Springer, 2007.

[6] Blau, P.J. (1992). "Friction, Lubrication, and Wear Technology" ASM Handbook 10th edition, ASM International, Materials Park, $\mathrm{OH}$.

[7] 7.Rachit Marwaha, Mr. Rahul Dev Gupta, Dr. Vivek Jain and Er. Krishan Kant Sharma., 2013, "Experimental Investigation \& Analysis of Wear Parameters on Al/Sic/Gr - Metal Matrix

[8] Hybrid Composite by Taguchi Method," Global Journal of Researches in Engineering, 13(09), 15-21.

[9] M. S. Sukumar, P. Venkata Ramaiah and A. Nagarjuna., 2014, "Optimization and Prediction of Parameters in Face Milling of Al-6061 Using Taguchi and ANN Approach,” Procedia Engineering, 97, 365 - 371.

[10] M.R. Sivakumar, N.V.R. Naidu., 2013, “Taguchi’s Orthogonal Array Approach to Study the Wear Behavior of Aluminum Alloy/Soda Lime Glass Composites,” International Journal of Engineering Research \& Technology, 02(08), 2328-2334.

[11] N. Naresh, K. Rajasekhar and P. Vijaya Bhaskara Reddy., 2013, "Parametric analysis of GFRP Journal of Mechanical and Civil Engineering, e-ISSN: composites in CNC milling machine using Taguchi method," IOSR 2278-1684 Vol 6, Issue 1, 102-111. 
Authors' Profile:

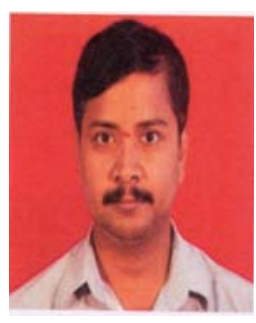

S Anandan was born in Mallur, salem District, India in 1964. He received the degree in Mechanical engineering from Institute of Mechanical Engineers, Mumbai, India in 2001 and completed M.Tech from PRIST University, India in 2014. Presently doing Ph.D. in Noorul Islam University ,Kumarakovil ,India. In the year 1986, he joined the department of Atomic Energy (Nuclear Power Corporation of India Ltd.,). As a technician and promoted as scientific officer in the year 2007. Presently working in Kundankulam Nuclear Power Project, India as an engineer in-charge, information center. He has got two Times Group Achievement Award in the department and he published an international journal paper in IJENM. He also attended many conferences (National and International) at various parts of India. 